\title{
El urbanismo contra lo urbano. La ciudad y la vida urbana en Henri Lefebvre
}

\author{
Manuel Delgado Ruiz
}

Afiliación: Universitat de Barcelona, España

Email: manueldelgado@ub.edu

Recibido: 28 de agosto del 2017

Aceptado: 13 de noviembre del 2017

\section{Manuel Delgado Ruiz}

Licenciado en Historia del Arte y Doctor en Antropología por la Universitat de Barcelona. Desde 1986 profesor titular de Antropología Social en la Universitat

de Barcelona. Coordinador de los grupos de investigación GRECS (Grup de

Recerca en Exclusió i Control Socials) y del GRACU (Grup de Recerca en

Antropologia del Conflicte Urbà).

\section{Resumen}

Henri Lefebvre coloca en el eje de su teoría sobre la vida urbana la oposición entre el espacio vivido por quienes lo usan o sueñan y el espacio abstracto que creen organizar los tecnócratas de la ciudad, que raramente reconocen hasta qué punto su "creatividad" está sometida a intereses privados o institucionales. Tras ese espacio hipotético sobre el que urbanistas y arquitectos trabajan no hay otra cosa que mera ideología, es decir, fantasma que recubre y disfraza las relaciones sociales reales de producción. Frente - 0 de espaldas- a ese orden espacial meramente teórico de los "especialistas", lo que las ciudades conocen es la actividad constante o inminente de lo urbano, entendido como apoteosis y exacerbación de lo social, dinamismo siempre activado de acontecimientos y quehaceres sobre el que los "expertos" aplican planes y proyectos, pero del que no saben en realidad nada, acaso por lo cual pugnan por anularlo.

Palabras Clave: espacio social; la ciudad; Lefebvre; lo urbano; urbanismo; vida urbana

Urban Planning Against The Urban. City and Urban Life in Henri Lefebvre

\begin{abstract}
Henri Lefebvre's theory about urban life is based on the pivotal opposition between the space which is lived by those who use it or dream about it, and the abstract space that city technocrats would like to organize -even if they are rarely aware of the extent to which their "creativity" is subjected to private or institutional interests. Behind this hypothetical space in which city planners and architects work is pure ideology, the ghost that covers and disguises real social relations of production. Facing -or even ignoring- that merely theoretical spatial order of the "experts", cities experience a constant and imminent activity that has to be understood as the apotheosis or essence of social relations. The urban is characterized by an intrinsic dynamism, always spun by developments and occurrences on which the "experts" implement plans and projects, even if they really ignore its real character - perhaps, this is the reason why they constantly try to deny it.
\end{abstract} Keywords: Lefebvre; the city; the urban; social space; urban life; urbanism. 


\section{La ilusión urbanística}

n su teoría del espacio, Henri Lefebvre (1974/2013, p. 90-92) distingue tres formas de conceptualizarlo, que se corresponden con otras tantas realidades diferenciadas, pero no por ello entrecruzándose constantemente: práctica espacial, espacios de representación y representaciones del espacio. La práctica espacial se corresponde con el espacio percibido, el más cercano a la vida cotidiana y a los usos más prosaicos, los lugares y conjuntos espaciales propios de cada formación social, escenario en que cada ser humano desarrolla sus competencias como ser social que se sitúa en un determinado tiempo y lugar. Son las prácticas espaciales las que segregan el espacio que practican y hacen de él espacio social. En el contexto de una ciudad, la práctica espacial se refiere a lo que ocurre en las calles y en las plazas, y los usos que estas reciben por parte de habitantes y viandantes (Lefebvre, 1974/2013, p. 97). Por su parte, los espacios de representación son los espacios vividos, los que envuelven los espacios físicos y los convierten en albergue de imágenes e imaginarios. Es espacio también de usuarios y habitantes, por supuesto, pero es propio de artistas, escritores, poetas, cineastas y filósofos que creen solo describirlo, pero que le añaden cualidades sensibles o morales que en sí no tenía. En los espacios de representación puede encontrar uno expresiones de sumisión a códigos impuestos desde arriba, pero también las expresiones del lado clandestino o subterráneo de la vida social. Es el espacio cualitativo de los sometimientos a las representaciones dominantes del espacio, pero también en el que beben y se inspiran las deserciones y desobediencias (Lefebvre, 1974/2013, p. 98).

Frente a esos espacios percibidos, practicados, vividos, Lefebvre coloca conceptualmente el espacio concebido, al que denomina representación del espacio (Lefebvre, 1974/2013, p. 99), en todo momento entrelazado con los otros dos -la práctica del espacio y el espacio de representación-, puesto que su ambición siempre es la de someterlos. En este caso es un espacio inicialmente solo teórico, pero que pugna por determinar el significado y el uso de los espacios sensibles de un modo $u$ otro, incluso, si es menester, mediante la fuerza. Esa representación del espacio -de la que el llamado espacio público sería actualización (Delgado, 2011)- es ideología aderezada con conocimientos científicos y disfrazada tras dialectos que se presentan como periciales que la hacen incuestionable, puesto que presume estar basada en saberes fundamentados. Ese es el espacio de los planificadores, de los proyectistas, de los administradores y de los administrativos, un espacio abstracto que es instrumento doctrinal clave a la hora de que el capitalismo intervenga y administre lo que siendo presentado como espacio, no deja de ser sino simplemente suelo, puesto que ese espacio acaba tarde o temprano, convertido en espacio inmobiliario, es decir espacio para vender. Ese es el espacio del poder, pero en el que "el poder no aparece como tal, sino que se disimula bajo la denominada 'organización del espacio'. Suprime, elude y evacúa todo cuanto se le opone mediante la violencia inherente y, si ésta no fuera suficiente, mediante la violencia expresa" (Lefebvre, 1974/2013, p. 357). Su finalidad es hegemonizar los espacios percibidos y vividos mediante sistemas de signos elaborados intelectualmente, es decir, mediante discursos. En su intervención en el Simposio Internacional de Sociología Urbana, celebrado en Barcelona en enero de 1973, Henri Lefebvre supo expresarlo con lucidez: "el arquitecto ya no es un hombre de dibujo; es un hombre de palabras" (1974, p. 226).

A cada momento, lo que pasa en tantas ciudades aporta nuevas pruebas de que Henri Lefebvre tenía y continúa teniendo razón en que lo propio de la tecnocracia urbanística es la voluntad de controlar la vida urbana real, que va pareja a su incompetencia crónica a la hora de entenderla. Es víctima de "la ilusión urbanística" (Lefebvre, 1972a, pp. 156169), dado que, considerándose a sí mismos gestores de un sistema, los expertos en materia urbana pretenden abarcar una totalidad a la que llaman la ciudad y ordenarla de acuerdo con una filosofía -el humanismo liberal- y una utopía, que es en esencia, como corresponde, una utopía tecnocrática. Su meta continúa siendo la de imponer la sagrada trinidad del urbanismo moderno: legibilidad, visibilidad, inteligibilidad. En pos de ese objetivo creen que pueden escapar de los determinantes que someten al espacio a las relaciones de producción capitalista, o reconducirlos. Su meta: conseguir 
que sus representaciones del espacio usurpen el lugar de la vida urbana real, que en el fondo detestan.

¿Cómo podríamos definir el vacío fundamental del urbanismo privado o público, nacido en el intelecto de unos o secreteado en las oficinas donde viven otros? En qué pretende reemplazar y suplantar la práctica urbana. No la estudia, pues precisamente esta práctica es para el urbanista un punto ciego. Vive en él, en él se encuentra, pero no lo ve y menos aún lo puede captar como tal. Con la conciencia tranquila, sustituye a la práctica en su representación del espacio, de la vida social de los grupos, de sus relaciones (Lefebvre, 1972a, p. 158).

A lo largo de La producción del espacio, Lefebvre (1974/2013) trabaja constantemente esta oposición entre espacio experimentado mediante el cuerpo o la imaginación espacio sensorial y sensual de la palabra, de la voz, de lo olfativo, de lo auditivo, pero también de lo recordado o soñado- y espacio concebido, que es el de arquitecto y el urbanista, espacio que, en forma de lote o porción, les ha sido cedido por el promotor inmobiliario o la autoridad política para que apliquen sobre él su "creatividad", que no es en realidad sino la sublimación de su plegamiento a intereses privados 0 institucionales. Como se ha señalado, tras ese espacio hipotético no hay otra cosa que mera ideología, en el sentido marxista clásico, es decir fantasma que recubre las relaciones sociales reales de producción, obstaculizando la revelación de su auténtica naturaleza y por tanto su transformación futura.

$Y$, puesto que no es más que ideología, ese espacio-conjetura está destinando, en cuanto se pretende convertir en realidad mediante el proyecto o el plan, a sufrir constantemente todo tipo de desgarros, desacatos y desmentidos que lo fragmentan como consecuencia de su falta de consistencia y su vulnerabilidad ante los envites de la naturaleza crónicamente conflictiva de la sociedad sobre la que pugna inútilmente por imponerse. El espacio que los "especialistas" se pasan el tiempo representando e intentado luego implantar es un espacio vacío y primordial, neutro, en condiciones de recibir contenidos fragmentarios e inconexos. Es, por definición, el espacio de las clases medias, precisamente porque ellas también son o quisieran ser neutras, y encuentran o creen encontrar en ese espacio "un espejo de su 'realidad', representaciones sedantes, la imagen de un mundo social en que tienen su lugar, etiquetado, asegurado" (Lefebvre, 1974/2013, p. 346), aunque la verdad es que ese es solo un efecto óptico, la consecuencia ilusoria de que esas clases medias han sido objeto de un falso alivio para unas aspiraciones que lo dado nunca satisfará.

\section{Ese espacio en que las cosas se juntan}

Otra de las clasificaciones conceptuales que le permite a Henri Lefebvre (1968/2016, pp. 81-88) reconocer diferentes niveles y dimensiones en la ciudad es la que resulta de aplicarle a su análisis un esquema semiológico. Haciéndolo, se encontraría, por una parte, la ciudad de la palabra, lo que se dice en las calles y las plazas, su habla. Luego está la lengua de la ciudad, que es la manera de decir lo que en ella se dice, las gestualidades; las formas y las formalidades. La escritura de la ciudad, por su parte, es lo que se escribe y se prescribe en sus muros, la disposición y el encadenamiento de los lugares; también remite al tiempo y las temporalidades. Aparte está esa estructura de significaciones al que los técnicos aplican su talento, pero que en el fondo solo sería un sistema de grafismos sobre el papel o, ahora, en la computadora; un conjunto ordenado de visualizaciones al que llaman urbanismo. Pero además de ser habla, lengua, escritura o grafismo, la ciudad sobre todo tiene un lenguaje que la trasciende, y que es justamente eso: lo urbano, es decir, el lenguaje urbano o, si se prefiere, lo urbano como lenguaje.

Para Lefebvre el lenguaje urbano sería lo que, siguiendo la semiótica de Greimas, podríamos llamar un orden de connotaciones. El habla, la lengua, la escritura y los grafismos de una ciudad actúan a la manera de un orden denotativo, en que cada término tiene una definición que lo agota como concepto (Greimas y Courtés, 1982, p. 107). En términos de la semiología clásica, esas formas de significar la ciudad constituirían una cadena sintagmática, esto es, un discurso -como todo discurso- lineal. En cambio, lo urbano -el lenguaje urbano- se conforma en torno a una infinidad de conexiones 
paradigmáticas. Habrá doctrinarios que quieran hacer de la ciudad un discurso, pero no podrán hacer lo mismo de lo urbano, porque lo urbano solo existe como inmensa estructura de asociaciones, de conexiones y desconexiones. Lo urbano, para Lefebvre, pone de manifiesto que la ciudad, concebida como un texto organizado por medio de un lenguaje, no puede ser en modo alguno una magnitud homogénea, puesto que, como recuerdan Greimas y Courtés, todo texto depende de varios sistemas diferentes y debe ser considerado a partir de la manera como se desarrolla su análisis y los niveles de pertinencia escogidos (1982, p. 108). De hecho, no podría existir un lenguaje denotativo, puesto que todo lenguaje no puede ser sino trama de connotaciones, a la manera como pusiera de manifiesto Hjelmslev (1943/1971, pp. 163-164), que, en su glosemática, impugna el supuesto según el cual, partiendo de un punto de vista vagamente sociológico, considera que la existencia de una norma social implica que una lengua nacional sea también uniforme y específica en su estructura interna.

Esa derivación semiológica en su teoría es lo que hace comprensible la distinción que Lefebvre plantea como central entre la ciudad y lo urbano. Lo apunta en el primer volumen de El derecho a la ciudad (1968/2016, pp. 71, 101-102) y lo desarrolla en uno de los capítulos del segundo, Espacio y política (1972/1976, pp. 63-71). La ciudad es una base práctico-sensible, una morfología, una realidad demográfica, un dato presente e inmediato, algo que está ahí. La ciudad es un conglomerado de volúmenes, infraestructuras, calles, plazas, actividades, etc. Lo urbano es otra cosa: no requiere por fuerza constituirse como elemento tangible, puesto que podría existir y existe como mera potencialidad, como conjunto de potencialidades, que no son otra cosa que la consecuencia de la labor de lo social como máquina constante de reunir, cruzar y mezclar.

Y porque es lenguaje, lo urbano no es nunca un tema, sino una sucesión infinita de actos y encuentros realizados o virtuales. Para Lefebvre, la vida urbana:

intenta que los mensajes, las órdenes, las presiones venidas de altas instancias se vuelvan contra ellas mismas. Intenta apropiarse del tiempo y el espacio, rompiendo con el dominio que estos establecen, apartándoles de su objetivo, cortocircuitándolos... Lo urbano sería así, más o menos, obra de los ciudadanos, en lugar de imponerse a ellos como un sistema, como un libro ya terminado (1968/2016, p. 88. El subrayado es suyo).

Lo urbano es esencia de ciudad, pero puede darse fuera de ella, porque cualquier lugar es bueno para que en él se desarrolle una sustancia social que acaso nació en las ciudades, pero que ahora expande por doquier su "fermento lleno de actividades sospechosas, de delincuencias y hogar de agitación. El poder estatal y los grandes intereses económicos difícilmente pueden concebir una estrategia mejor que la de devaluar, degradar y destruir la sociedad urbana..." (Lefebvre, 1968/2016, p. 101). Lo urbano es todo aquello que se escapa a la fiscalización de poderes que no entienden ni saben qué es y que, acaso por ello, se esfuerzan por

"consolidar lo que se opone a la sociedad urbana, lo que la niega y la destruye en el transcurso del proceso mismo que la crea, a saber, la segregación generalizada, la separación sobre el terreno de todos los elementos y aspectos de la práctica social, disociados los unos de los otros y reagrupados por decisión política en el seno de un espacio homogéneo (Lefebvre, 1968/2016, p. 99).

Ahora bien, a pesar de los ataques que constantemente recibe lo urbano y que procuran desmoronarlo, o al menos desactivarlo, sostiene Lefebvre, este persiste e incluso se intensifica, puesto que "las relaciones sociales continúan ganando en complejidad, multiplicándose e intensificándose, a través de las contradicciones más dolorosas. La forma de lo urbano, su razón suprema, a saber, la simultaneidad y la confluencia, no pueden desaparecer. La realidad urbana, en el seno mismo de su fragmentación, persiste" (1968/2016, pp. 101-102). Es más, se antoja que la racionalización paradójicamente absurda que pretende destruir la ciudad ha traído consigo una intensificación de lo urbano y sus problemáticas. El mérito de ello corresponde a habitantes y usuarios que, a pesar de los zarandeos que recibe un estilo de vida que no deja nunca de enredarse sobre sí mismo, o quizás como reacción ante ellos, "reconstruyen los centros, utilizan los lugares para aún las más sencillas formas de encuentro" (1968/2016, p. 102). Frente a un control sobre la ciudad por parte de sus poseedores políticos y económicos, que quisieran convertirla en valor de cambio y que no dudan en emplear todo tipo de 
violencias para ello, lo urbano escapa de las exigencias del valor de cambio, dado que es el reino del cambio y el encuentro liberados del valor de cambio (1968/2016, p. 167). Es posible que la ciudad esté o llegue a estar muerta, pero lo urbano persistirá, aunque sea en "un estado de actualidad dispersa y alienada, en un estado embrionario, virtual. Lo que la vista y el análisis perciben sobre el terreno puede pasar, en el mejor de los casos, por la sombra de un objeto futuro en la claridad de un sol amaneciendo" (1968/2016, p. 127). De hecho, "la vida urbana todavía no ha comenzado" (1968/2016, p. 129).

Lo urbano no es substancia ni ideal: es más bien un espacio-tiempo diferencial. Es lo que no pertenece propiamente a la ciudad; es más, se constituye, hace notar Lefebvre (1972/1976, p. 83), en lo que permite ver realizado el paso que, postulado por Engels (1878/1968, pp. 314-315) en su Anti-Dühring, y, antes que él, por Charles Fourier (1808/1974, pp. 22-28), permitiría superar -hasta llegar un día a olvidar- la primera forma de división del trabajo: la separación del campo y la ciudad, que, una vez suprimida, permitiría la restauración de lo social al reino de la naturaleza. Será así, puesto que, para Lefebvre (1968/2016), lo social habrá devenido ya del todo urbano -ni rural, ni urbanizado, es decir sometido al urbanismo-, puesto que lo urbano es ya sino la radicalidad misma de lo social, su exacerbación y, a veces, su exasperación. "Lo urbano, al mismo tiempo que lugar de encuentro, convergencia de comunicaciones e informaciones, se convierte en lo que siempre fue: lugar de deseo, desequilibrio permanente, sede de la disolución de normalidades y presiones, momento de lo lúdico y lo imprevisible" (1968/2016, p. 102). Es lo que aporta "movimiento, improvisación, posibilidad y encuentros. Es un 'teatro espontáneo' o no es nada" (1968/2016, p. 160].

Lo urbano es descrito y analizado en los dos volúmenes de El derecho a la ciudad como un auténtico espacio hipersocial, lo que es congruente con que luego calque sus características a lo que, en La producción del espacio, Lefebvre (1974/2013, p. 141 147) llama espacio social, categoría que agrupa una pluralidad ilimitada de espacios sociales. Es más, esa identificación es explícita en diversos momentos, puesto que en sus dos obras anteriores ya establecía sosteniendo que el espacio social se ha vuelto ya urbano en su conjunto. En efecto,

el espacio social, sobre todo el espacio urbano aparece en su multiplicidad, comparable a la de un hojaldre, mucho más que a la homogeneidad del espacio euclidiano clásico. Los espacios sociales se compenetran, se interfieren, se superponen, incluso cuando se antojan separados por muros, puesto que ni siquiera estos pueden evitar la circulación de los fluidos que no dejan de recorrerlo. En ello consiste su extraordinaria complejidad, hecha de "unidades individuales y particularidades, puntos fijos relativos, movimientos, flujos y ondas, los unos se compenetran, los otros se enfrentan, etc. (1974/2013, p. 143).

Interesante la afinidad entre el pensamiento de Lefebvre y el de Jane Jacobs, que compartía con él su antipatía hacia el urbanismo, esa "pseudociencia", con su "plétora de sutiles y complicados dogmas [...], levantados sobre cimientos idiotas" (1961/2011, p. 39). Porque, ese espacio urbano que Lefebvre teoriza como espacio de y para 10 urbano, ¿acaso no es ese dominio al que se refería Jacobs al hacer el elogio de la sociedad de las aceras, ese escenario para una compleja y apasionante vida colectiva, en la que las ciudades encontraban el elemento fundamental que hacía de ellas marco para las formas más fértiles y creativas de convivencia humana? En efecto, Jacobs nos habla de un tipo específico de sociabilidad que protagonizan los transeúntes o avecindados que llevan a cabo actividades más o menos ordinarias a lo largo y ancho de la acera de una calle, distribuyéndose en una plaza u ocupando el que consideran su lugar en un jardín público, que no sólo constituían una colección fascinante de actos y acciones coordinador a la manera de un verdadero "orden complejo" (1961/2011, p. 77), conformado por microprocesos en los que más que la compenetración entre factores orgánicos integrados, lo que se daba era un "intrincado ballet" (1961/2011, p. 78 ), es decir, una suite de iniciativas armonizadas en secreto, altamente eficaces, en condiciones de dotar de congruencia interna una masa de unidades en permanente agitación.

De ahí que Jacobs, con un lenguaje llano y a partir de una estimación directa de la realidad, reconozca en una calle, un parque público o un barrio, ejemplos de lo que ella misma imagina como una suma de movimientos y actividades, la mayoría de 
ellos triviales y casuales, pero cuya suma no lo es en absoluto, a la manera de lo que los teóricos del caos y de los sistemas complejos llamarán estructuras disipativas y lejos del equilibrio, fuentes paradójicas de nuevas coherencias que gozan de una cierta autonomía respecto de las condiciones del entorno y que se pasan el tiempo generando fenómenos de autoorganización. Algo que los propios teóricos de la complejidad no tenían inconveniente en reconocer. Al llevar estos espacios los procesos termodinámicos y metabólicos que generan orden a partir de una excitación molecular que podría antojarse caótica al campo de la actividad humana, no podían dejar de señalar cómo esa misma paradoja se encuentra en la capacidad creativa de lo que Simmel había llamado la "nerviosidad" de la vida en las ciudades: "La intensificación de las relaciones sociales que favorecen la vida urbana, por ejemplo, ¿no ha sido la vez fuente de deshechos, de polución, y de invenciones prácticas, artísticas e intelectuales?" (Prigogine y Stengers, 1990, p. 66).

La calle es, en efecto, el proscenio predilecto para que en él se concrete lo urbano, en el sentido que Lefebvre propone. Es ahí donde podemos contemplar cómo se despliega un orden social gestionado en buena medida desde su propio interior, en el que se mezclan acontecimientos grandes y microscópicos, conductas pautadas y comportamientos marginales, monotonías y sorpresas, lo anodino y lo excepcional, lo vulgar o lo misterioso, permanencias y mutaciones, lo indispensable y lo superfluo, las certezas y la aventura. Un "desorden" que produce y al tiempo desmiente el orden, en que nada hay uniforme ni inerte, un universo en que no dejan de producirse diferencias y sucesos, a veces infinitesimales, algunos de los cuales serán proveedores de sentido. ¿Acaso ese marco en que lo más improbable está siempre a punto de ocurrir, aquel en el que siempre se insinúa y a veces irrumpe lo "posible imposible" que apremiaba Lefebvre (1972b, pp. 50-52), estallido de rabia, goce y frenesí cuyo escenario y vehículo solo podrá ser la vida urbana?

Lo urbano se alza así como horizonte, forma y luz (virtualidad que ilumina), al mismo tiempo que como practica en marcha, fuente y fundamento de otra naturaleza, de una naturaleza diferente de la inicial $Y$ eso través de las representaciones mixtas demasiado rápidamente disociadas aquí en un breve análisis: mito y utopía, ideología y ciencia. La problemática urbana se anuncia ¿Qué saldrá de ese hogar, de ese fogón de brujas, de esa intensificación dramática, de las potencias creadoras, de las violencias, de ese cambio generalizado en el que no se ve qué es lo que cambia, excepto cuando se ve excesivamente bien: dinero, pasiones enormes y vulgares, sutilidad desesperada? La ciudad se afirma; después estalla (Lefebvre, 1972a, p. 114).

Subrayemos lo que Lefebvre proclama: "en tanto que forma, lo urbano lleva un nombre: es la simultaneidad" (1972/1976, p. 69). Simultaneidad de percepciones, de acontecimientos, espacio por tanto de intensificación y generalización de todas las confluencias, puesto que es la forma concreta que adopta "el encuentro y la reunión de todos los elementos que constituyen la vida social" (Lefebvre, 1972/1976, p. 68). En el marco general definido por todo tipo de procesos negativos de dispersión, de fragmentación, de segregación, lo urbano se expresa como exigencia contraria de conjunción, de reunión, de redes y flujos de información y comunicación. "Lo que la forma urbana reúne y torna simultáneo puede ser muy diverso. Tan pronto son cosas, como personas, como signos; lo esencial reside en la reunión y en la simultaneidad" (Lefebvre, 1972/1976, p. 69). Ese espacio en que se intensifican y generalizan los intercambios y las coincidencias, ¿no se parece o es idéntico a aquel en el que Clarisse Dalloway -es decir, de alguna manera la propia Virginia Woolf (1925/1993)-, recibía la impresión, mientras cruzaba Victoria Street, de que allí, en aquel momento, "las cosas se juntaban"? 


\section{Referencias Bibliográficas}

Delgado, M. (2011). El espacio público como ideología, Madrid: Los Libros de la Catarata.

Engels, F. (1878/1968). Anti-Dühring, Madrid: Ciencia Nueva.

Fourier, C. (1808/1974). Teoría de los cuatro movimientos, Barcelona: Barral.

Greimas, A.J. y Courtés, J. (1982). Semiótica. Diccionario razonado de teoría del lenguaje, Madrid: Gredos.

Hjelmslev, L. (1943/1971). Prolegómenos a una teoría del lenguaje, Madrid: Gredos.

Jacobs, J. (1961/2011). Muerte y vida de las grandes ciudades, Madrid: Capitán

Lefebvre, H. (1972a). La revolución urbana, Madrid: Alianza Editorial.

Lefebvre, H. (1972b). Más allá del estructuralismo, Buenos Aires: La Pléyade.

Lefebvre, H. (1974) La producción del espacio, Papers de sociologia, 3, 219-229.

Lefebvre, H. (1972/1976). Espacio y política, Barcelona: Península.

Lefebvre, H. (1974/2013). La producción del espacio, Madrid: Capitán Swing.

Lefebvre, H. (1968/2016). El derecho a la ciudad. Madrid: Capitán Swing.

Prigogine, I. y Stengers, I. (1990). Entre el tiempo y la eternidad. Madrid: Alianza Editorial.

Woolf, V. (1925/1993). La señora Dalloway, Barcelona: Lumen. 